\title{
Structural Assignment of Poecillastrins B and C, New Macrolide Lactams from the Deep-Water Caribbean Sponge Poecillastra Species ${ }^{\#}$
}

Kentaro Takada, Byoung W. Choi, Mohammad A. Rashid, William R. Gamble, John H. Cardellina, 11, Que N. Van, John R.

Lloyd, James B. McMahon, and Kirk R. Gustafson

S1 $\quad{ }^{1} \mathrm{H}$ NMR spectrum of poecillastrin B (1) in DMF- $d_{7}$.

S2 COSY spectrum of poecillastrin B (1) in DMF- $d_{7}$.

S3 TOCSY spectrum of poecillastrin B (1) in DMF- $d_{7}$.

S4 HSQC spectrum of poecillastrin B (1) in DMF- $d_{7}$.

S5 HMBC spectrum of poecillastrin B (1) in DMF- $d_{7}$.

S6 $\quad{ }^{1} \mathrm{H}$ NMR of poecillastrin C (2) in DMF- $d_{7}$.

S7 COSY spectrum of poecillastrin C (2) in DMF- $d_{7}$.

S8 TOCSY spectrum of poecillastrin C (2) in DMF- $d_{7}$.

S9 HSQC spectrum of poecillastrin C (2) in DMF- $d_{7}$.

S10 HMBC spectrum of poecillastrin C (2) in DMF- $d_{7}$. 


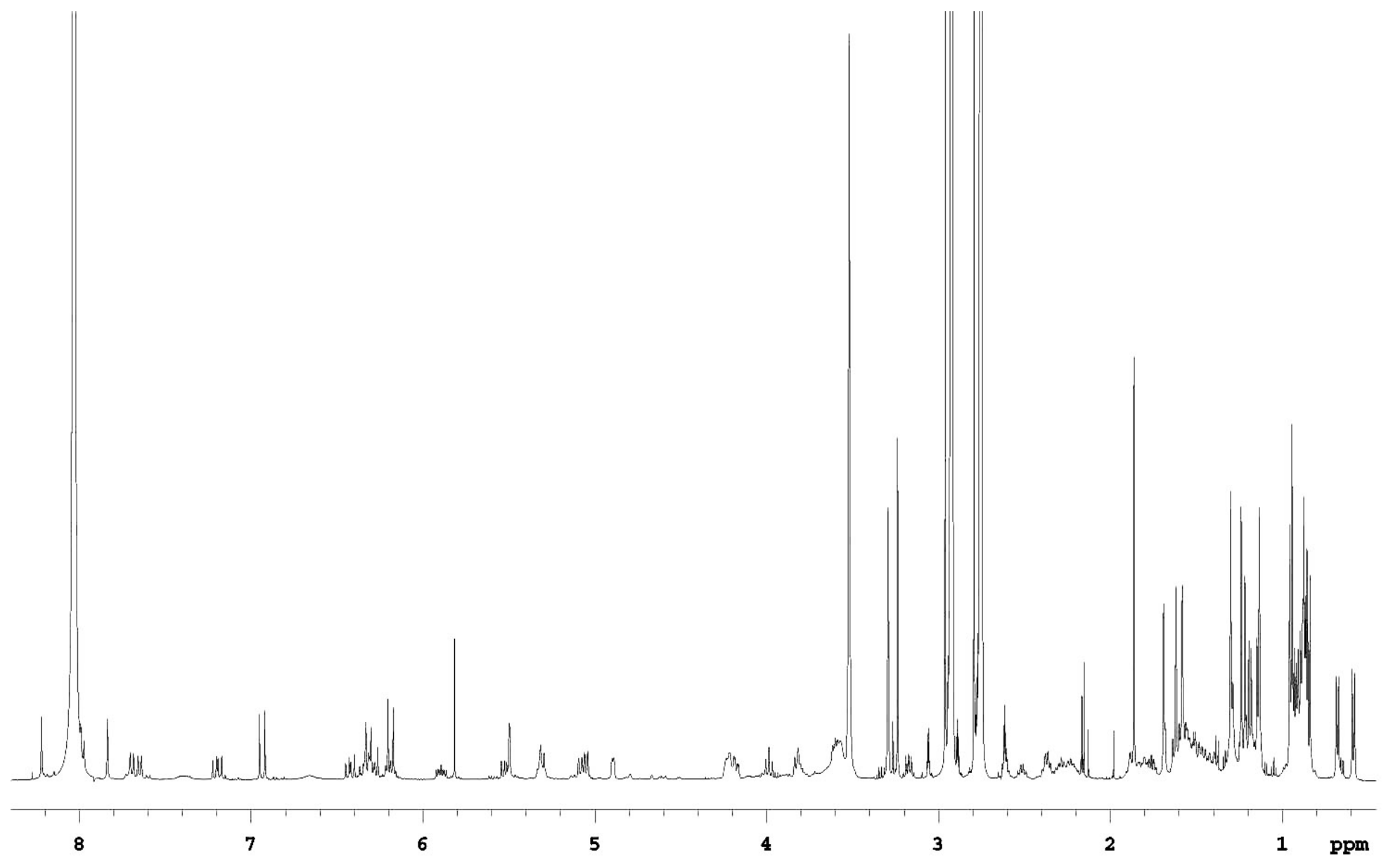

S1 $\quad{ }^{1} \mathrm{H}$ NMR of poecillastrin B (1) in DMF- $d_{7}$. 


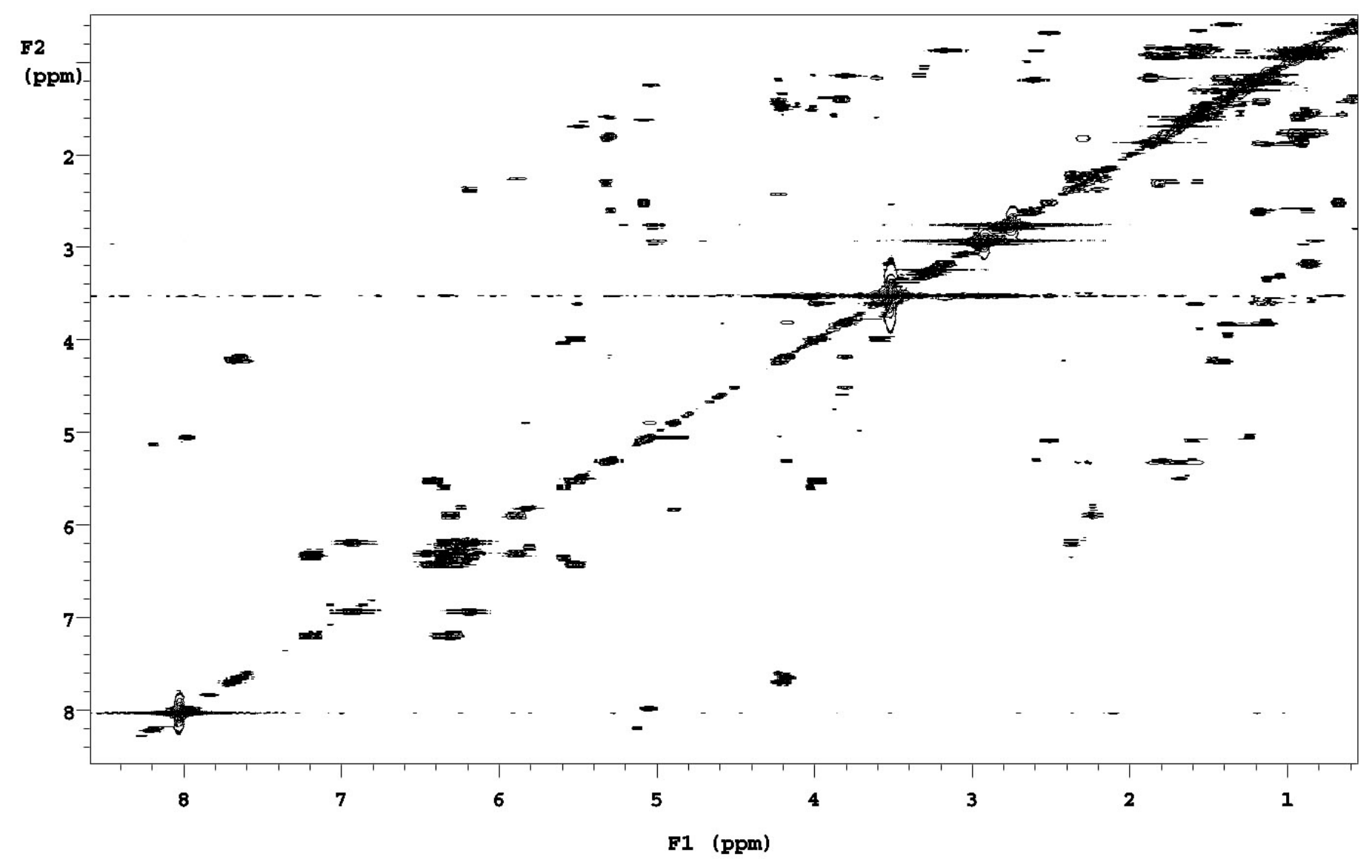

S2 COSY spectrum of poecillastrin B (1) in DMF- $d_{7}$. 


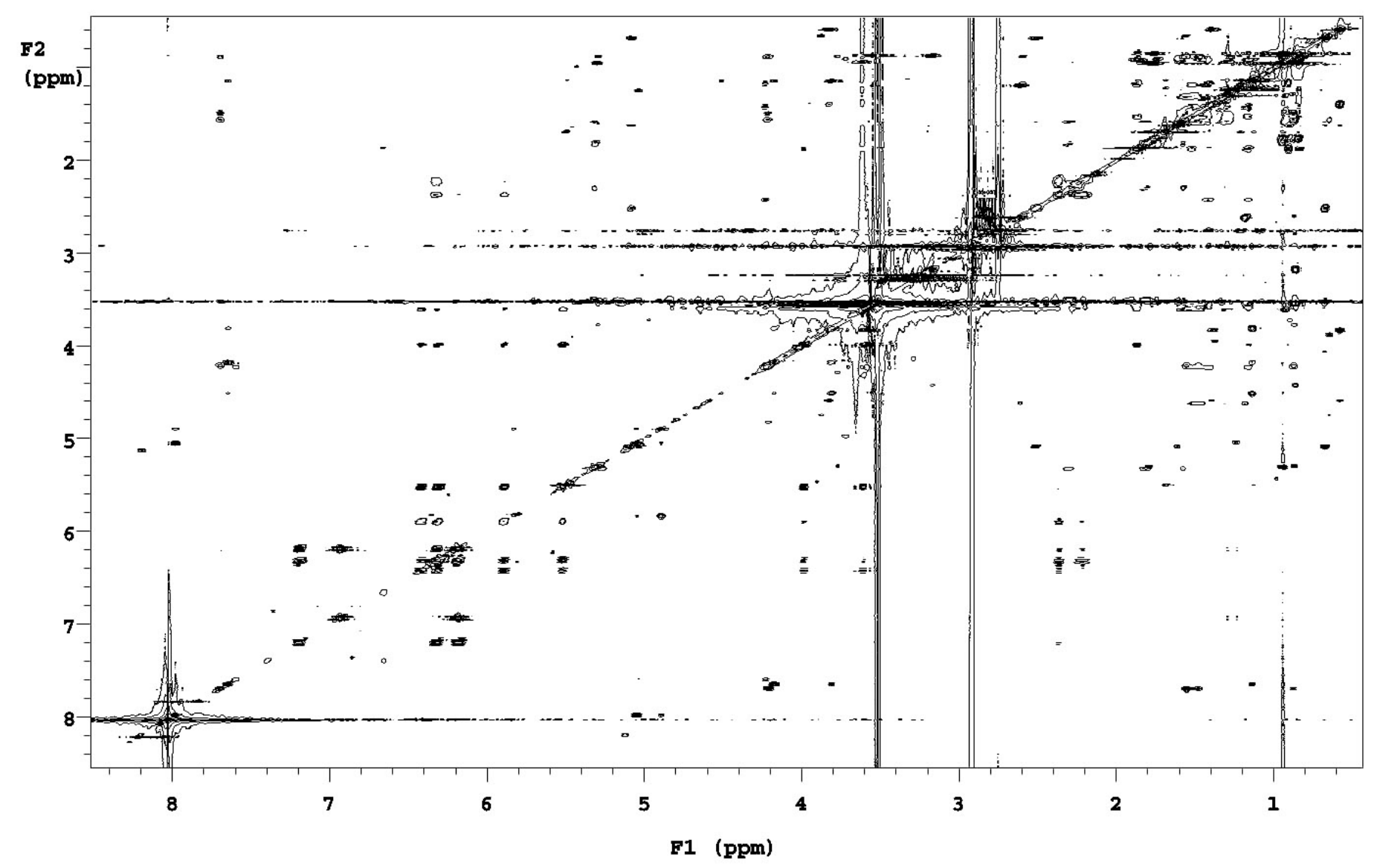

S3 TOCSY spectrum of poecillastrin B (1) in DMF- $d_{7}$. 


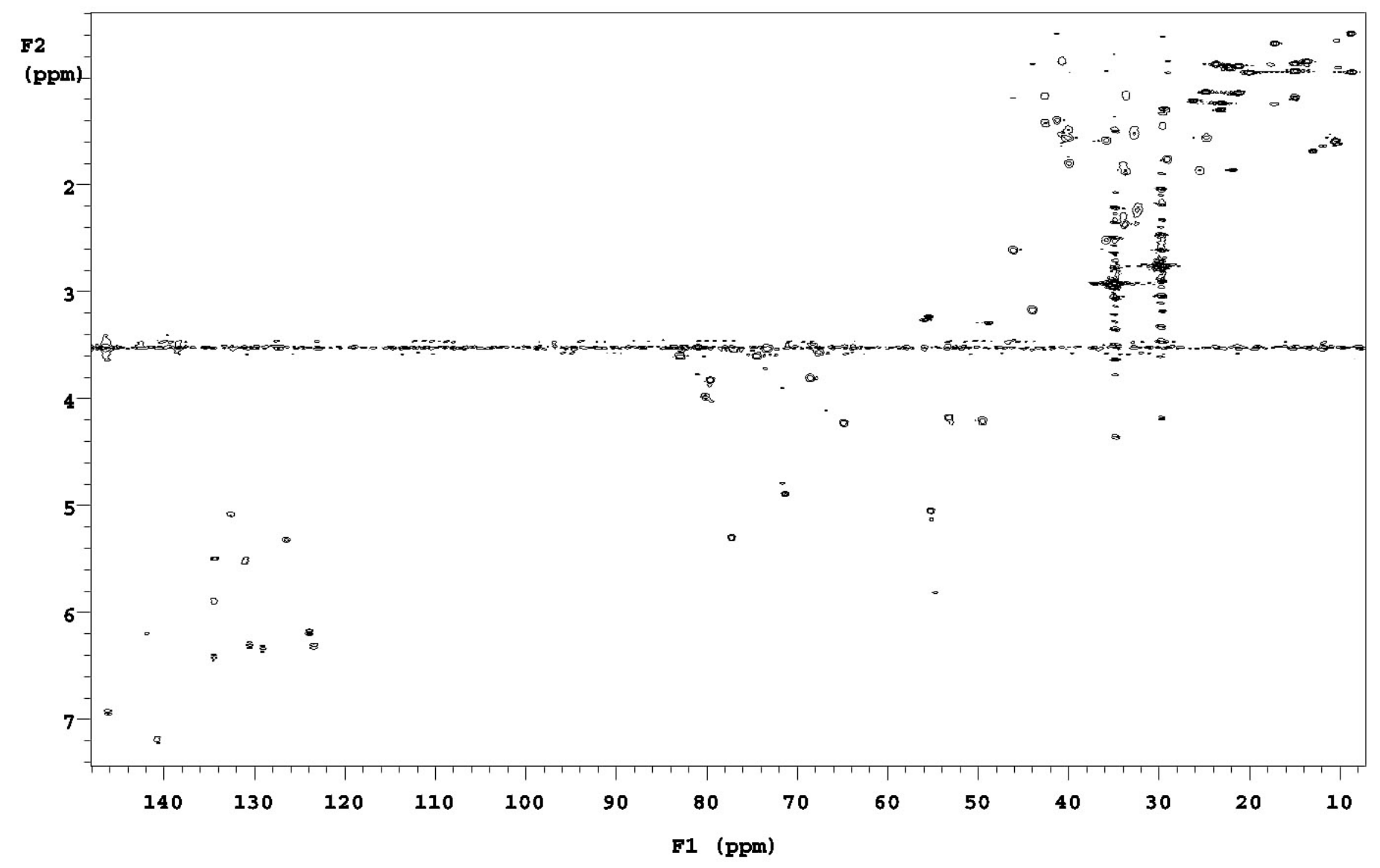

S4 HSQC spectrum of poecillastrin B (1) in DMF- $d_{7}$. 


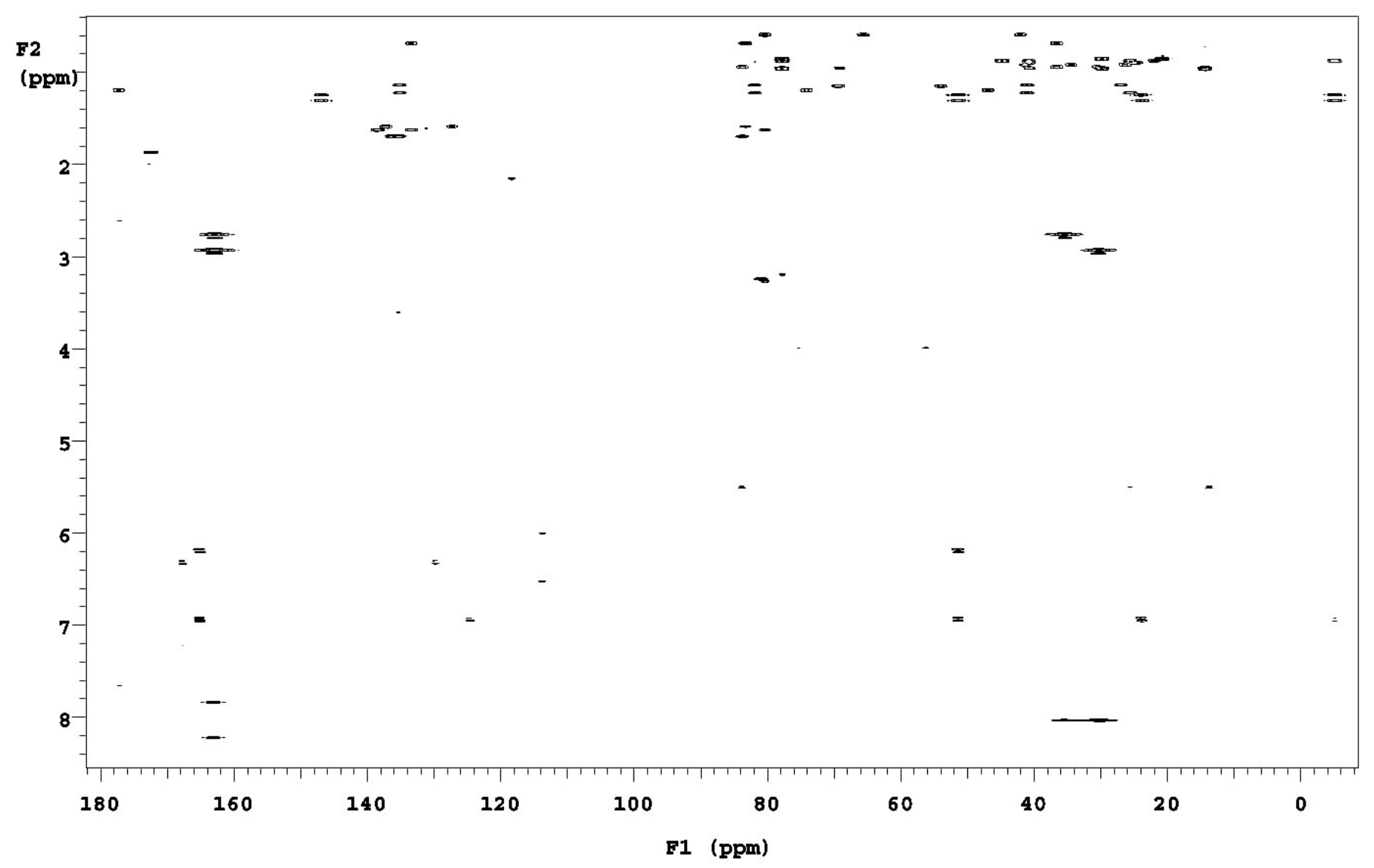

S5 HMBC spectrum of poecillastrin B (1) in DMF- $d_{7}$. 


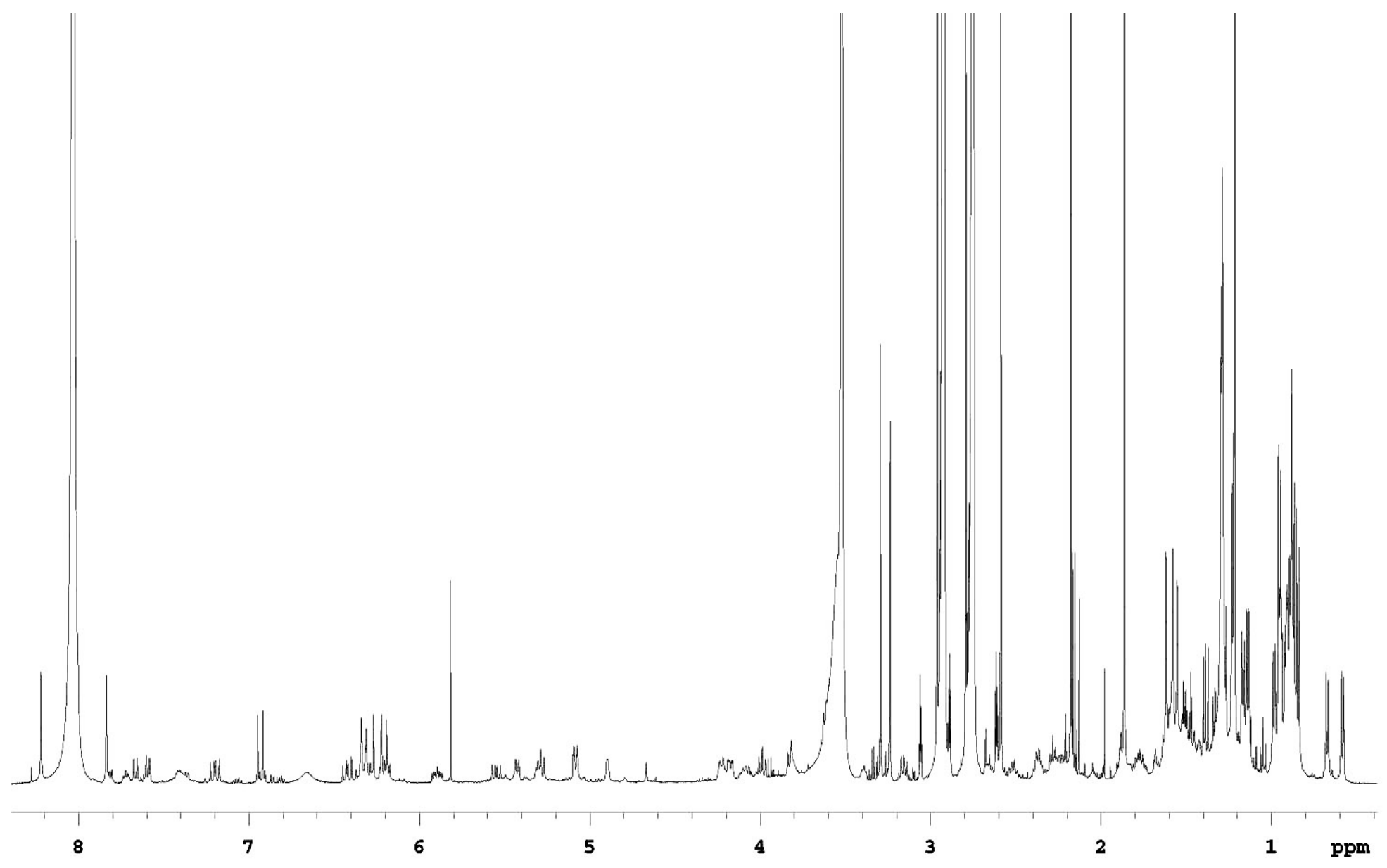

S6 $\quad{ }^{1} \mathrm{H}$ NMR of poecillastrin C (2) in DMF- $d_{7}$. 


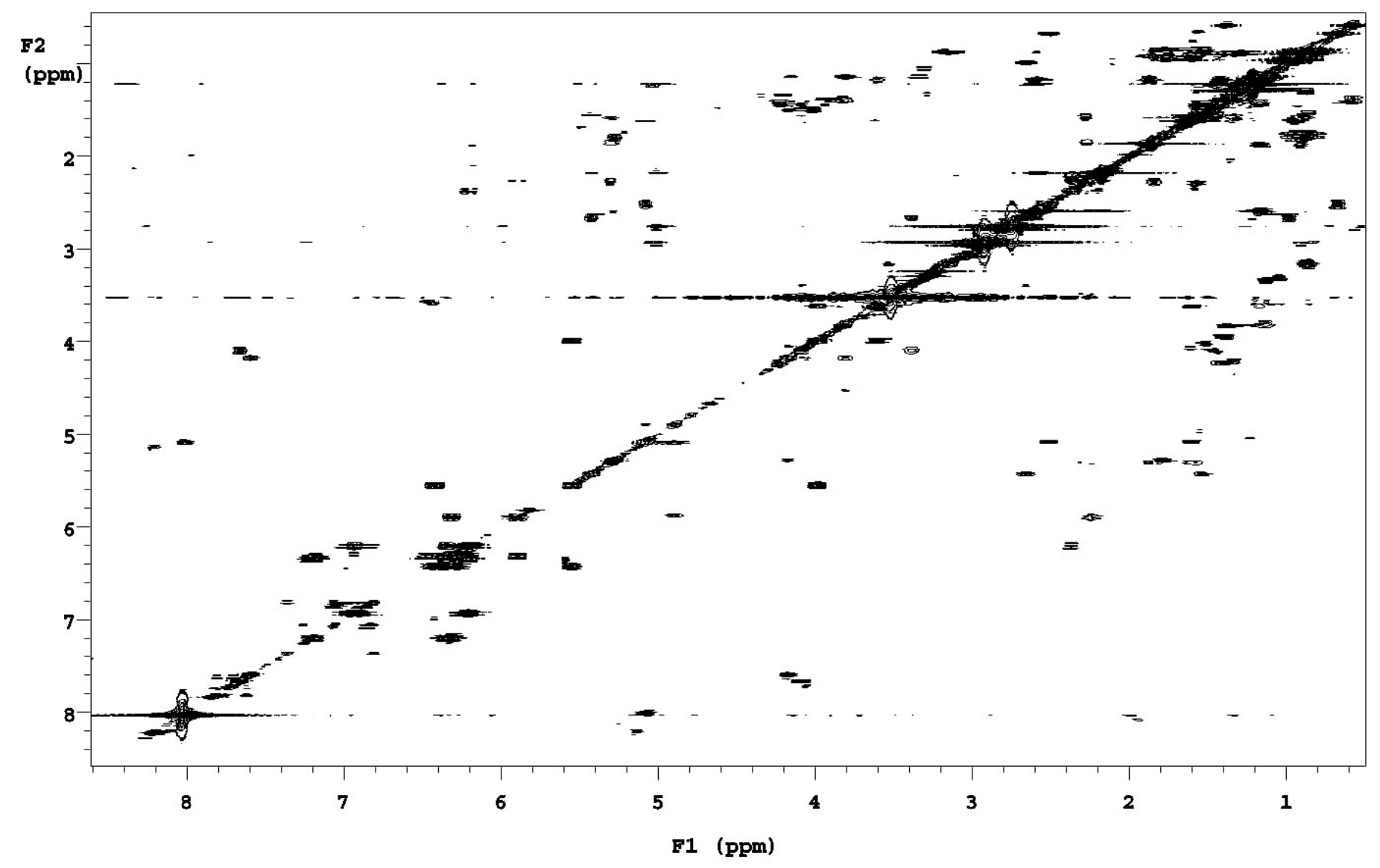

S7 COSY spectrum of poecillastrin C (2) in DMF- $d_{7}$. 


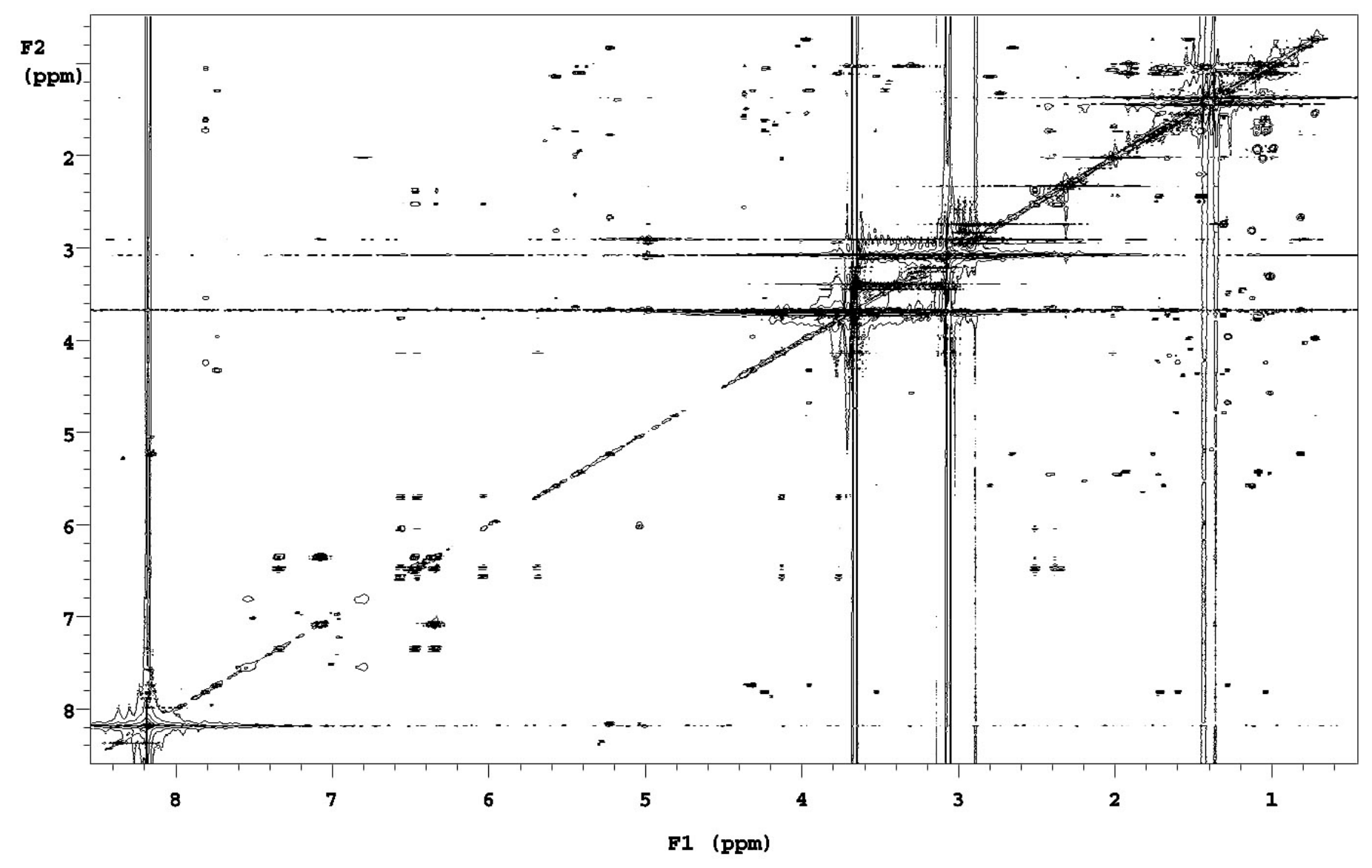

S8 TOCSY spectrum of poecillastrin C (2) in DMF- $d_{7}$. 


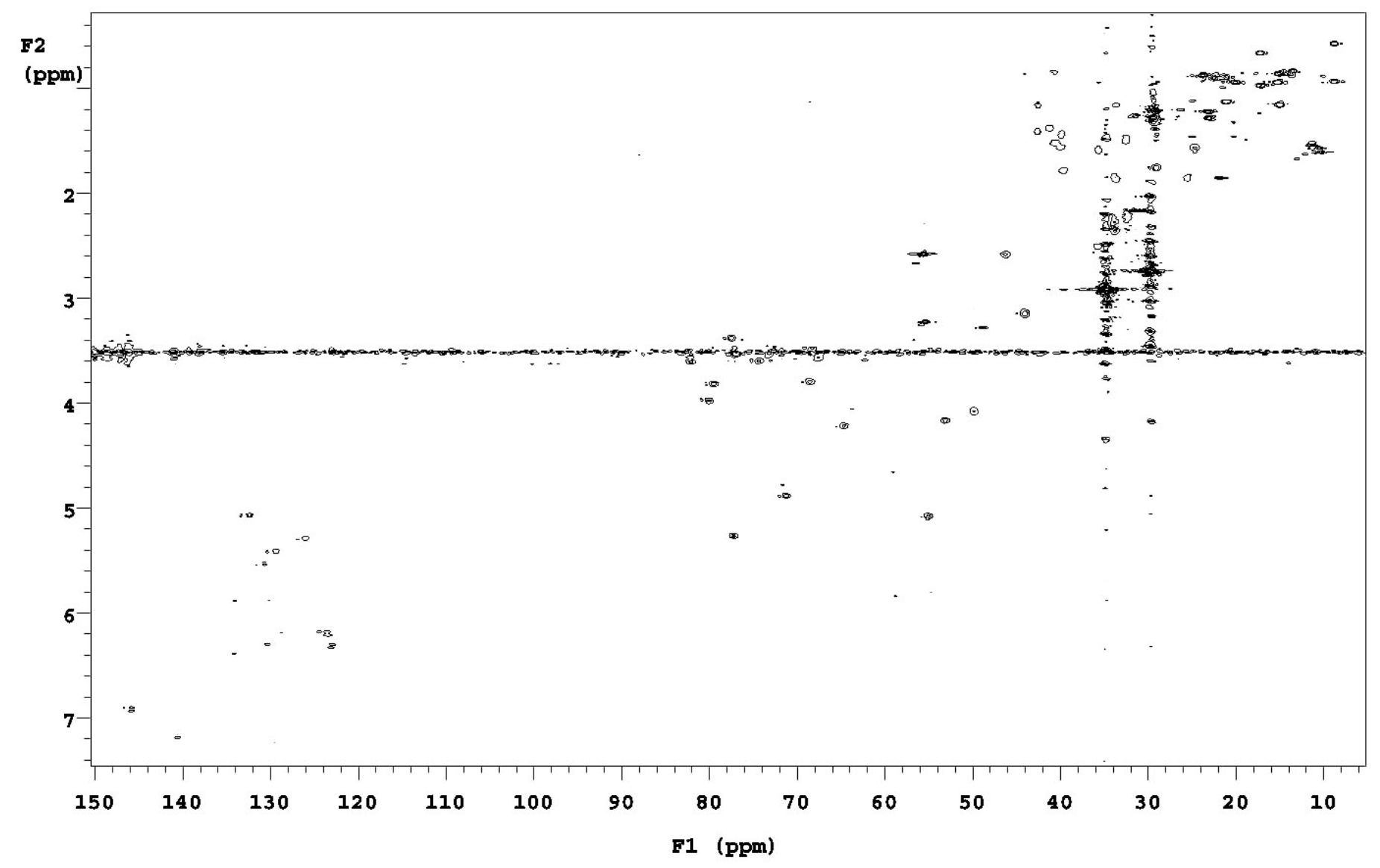

S9 HSQC spectrum of poecillastrin C (2) in DMF- $d_{7}$. 


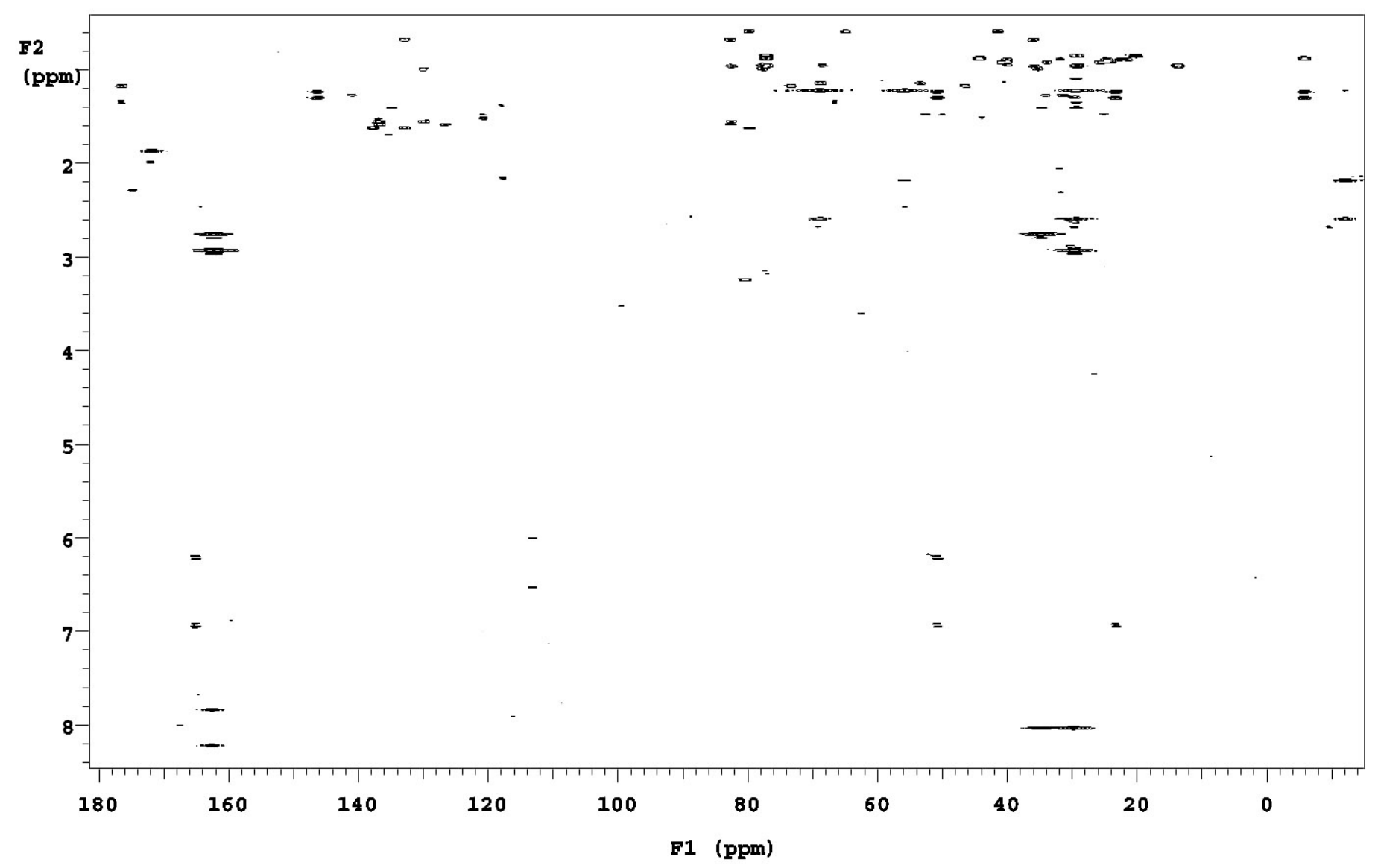

S10 HMBC spectrum of poecillastrin C (2) in DMF- $d_{7}$. 